REVIEW

\title{
Effects of the civil procedure rules on clinical negligence claims
}

\section{K Mayberry}

Postgrad Med J 2003;79:74-77

The frequency with which clinicians can expect to face allegations of clinical negligence and court proceedings related to those allegations is likely to increase in coming years. The processes of investigation and defence have been modified by the introduction of the Civil Procedure Rules in 1999. This review outlines these developments and emphasises the need for speedy and comprehensive responses by doctors involved in such procedures.

Correspondence to: Mrs Margaret Mayberry, Leicester General Hospital, Gwendolen Road, Leicester LE5 4 PW, UK

mkmayberry@yahoo.co.uk

Submitted 11 August 2002 Accepted 18 September 2002
T he introduction of the Civil Procedure Rules in 1999 changed the way claimants and the defence deal with clinical negligence issues. These new rules were introduced in response to the mounting costs and delays that many litigants experienced in this area. In my analysis of the impact of these rules on clinical negligence practice I will look at the background to these new rules, the role of pre-action protocols, the judge and expert witnesses, as well as alternative approaches such as mediation. The impact of these procedures on speedier justice for the claimants and the human rights of the defence will be important issues in reaching a conclusion.

\section{BACKGROUND}

In the introduction to Access to Justice in July 1996 Lord Woolf wrote that:

"Effective access to the enforcement of rights and the delivery of remedies depends on an accessible and effective system" ${ }^{\prime}{ }^{1}$

This became the guiding principle of the report, which sought to remedy the injustices that were thought to characterise the old civil justice system. His committee identified the following basic principles as being important for the delivery of justice:

- Just.

- Fair and be seen to be so by:

(a) ensuring that litigants have an equal opportunity, regardless of their resources, to assert or defend their legal rights;

(b) providing every litigant with an adequate opportunity to state his own case and answer his opponent's;

(c) treating like cases alike.

- Procedures and cost should be proportionate to the nature of the issues involved.

- Speedy.

- Understandable to those who use it.
- Responsive to the needs of those who use it.

- It should provide as much certainty as the nature of particular cases allows.

(Paraphrased from Access to Justice. ${ }^{1}$ )

He also recognised that for such a system to be effective it must be adequately resourced and organised. The report saw the key problems in contemporary civil litigation as being due to cost, delay, and complexity.

From the background research reported in the Annex to Access to Justice by Professor Hazel Genn we have some ideas on the costs of litigation. Fewer than $10 \%$ of medical negligence bills came in at under $£ 10000$, one third at $£ 40000$ or more, and just under a quarter at $£ 50000$ or more. These costs have been increasing by about $7 \%$ a year during the last decade. One of the major sources of these costs has been at the prelitigation stage. Much of the reform brought in by the Civil Procedure Rules has concentrated on streamlining this stage of litigation.

In the case of medical or clinical negligence there had been a mean delay between instruction and issue of 21 months with a total duration of 65 months for the average case. Interestingly the report acknowledges that the duration of cases has changed little over recent years with both light and heavy cases being of similar length. Indeed the only significant variable between cases was whether the winning party had legal aid and this tended to extend the duration of cases by $25 \%$. The fact that $92 \%$ of all cases were in receipt of legal aid is an indication of the nature of the majority of claimants-lone individuals dealing with an established bureaucracy.

The complexity of clinical negligence cases includes issues of patient understanding of both medical and legal jargon and the ensuing difficulty of proving causation and negligence. In addition work by Vincent $e t$ al identified a range of motives for suing doctors which included a need to know what had gone wrong and a wish to prevent similar incidents happening again. ${ }^{2}$ The interplay between such emotional factors was recognised by Lord Woolf when he wrote of "the importance of establishing at the outset what an injured patient wants". ${ }^{\prime}$

In addition to providing a more just, fair, speedy, and proportionate response in the area of clinical negligence, Woolf was concerned with unmeritorious cases which were often pursued and clear cut claims which were defended too long. Such cases contributed to the unacceptable delays that characterised clinical negligence cases before his reforms. The fact that probably $90 \%$ of these claims were legally aided meant an increasing burden on the public purse with both litigants 
and defendants being funded from that source. The estimated cost to the NHS of defending and meeting claims of negligence in 1996-97 was £235 million pounds, with a growth rate of $25 \%$ a year. ${ }^{3}$ However, disproportionately high costs also meant that smaller claims were rarely litigated.

Further difficulties which were identified included a reluctance of the defendants to initiate a thorough investigation of untoward incidents in the knowledge that patients often give "little or no notice of a firm intention to pursue a claim"1 and that few such incidents led to litigation. The use of expert witnesses had also become rather partisan and they were often seen "as part of the team which investigates and advances a party's contentions" and subsequently "a very effective weapon in the parties' arsenal of tactics". ${ }^{1}$ The ideal role for such an expert was defined by Lord Wilberforce in The Ikarian Reefer where he stated "that expert evidence presented to the court should be and should be seen to be the independent product of the expert uninfluenced as to form or content by the exigencies of litigation". ${ }^{4}$

\section{THE REFORMS}

Woolf proposed a radical series of changes to the civil procedure rules with special attention to the problems encountered in clinical negligence. These may be summarised as:

- Avoid litigation if possible.

- If litigation is essential it should not be complicated.

- Litigation should be shorter and less expensive.

- A spirit of cooperation should exist between the parties

- Parties should help the court.

- Judges should control the progress of cases.

- The court should be tailored to the needs of litigants.

The purpose of these changes is to reduce tactical delays and prevent inappropriate adversarial contests, which were seen as major contributors to the costs and delays in achieving a just outcome. The mechanism by which this approach should be administered is through case management and case allocation. Woolf felt that this would result in:

" 4 a. Clearer statements of claim and fully pleaded defences should speed up the process of cases by helping to establish a factual matrix and define the real issues at an earlier stage.

b. Claimants offers will encourage earlier settlements on realistic terms.

c. Extended summary judgment may help to weed out weak claims or defences at an earlier stage".

In order to achieve these ends judges needed "improved training and greater specialisation" so enabling them "to identify weak cases ... determine issues ... limit the scope of evidence". ${ }^{1}$ It is interesting to speculate whether such an approach could eventually lead to the emergence of specialist courts which would deal only with medical negligence cases. Some support for this view comes from Lord Woolf's suggestion that "special lists in the Queen's Bench Division should include a separate medical negligence list".

In order to ensure that cases are dealt with quickly and efficiently they are allocated to one of three "tracks" which are:

Small claims: This deals with cases worth under $£ 5000$.

Fast track: For cases worth $£ 5000$ to $£ 15000$ and lasting about one day in court.

Multitrack: For more complex cases and those likely to last longer than one day.

In addition to better training of judges and clear timetabling of cases within one of these tracks, case management requires the use of pre-action protocols. These are characterised by the following:
- Any complaint should initiate a proactive investigation by the healthcare provider in anticipation of legal action.

- Requests for records by the patient or his/her advisor will be met within 40 days.

- Letters of claim will follow a standard template and give details of the claim and its value, together with costs. This must be acknowledged by the health provider within 14 days, who also will identify who will deal with the claim.

- Within three months the health provider must return a detailed letter of response, making admissions of liability and/or a detailed rebuttal of criticisms which are rejected. Admissions will be binding.

- The health provider must give a reasoned response to any offer from the claimant to settle.

- By three months the matter must have been reported to the National Health Service Litigation Authority (NHSLA).

- The defence must be served within 28 days, although by mutual agreement this can be extended to 56 days.

- The defence must be supported by a "statement of truth".

In order to sharpen the procedure as part of the pre-action protocol defending trust or health authorities are required to select appropriate documents for disclosure to the claimant, so preventing the case being lost under a morass of irrelevant paperwork. Documents that must be disclosed include any which:

- Adversely affect the defendant's own case.

- Adversely affect another party's case.

- Support another party's case.

- They have been required to disclose through a relevant party direction.

These documents must be supplied in an appropriate format, which is defined within the protocols and includes details of paper size, legibility, and the absence of punched holes. Documents not disclosed cannot be relied upon later, as it is unlikely that the judge will grant leave for their introduction. The use of such pre-action protocols will sharpen the approach to the case by the healthcare provider. Timetabling the presentation of information will mean that the claimant will rapidly receive all appropriate documentation related to his or her case and that information will be available in a clearly legible format.

Such pre-action protocols mean that weak cases where the claim is feeble or the defence unmaintainable will be settled quickly. Under the new rules both parties can seek to show that the opponent has "no real prospect of success" and so apply for summary judgment. This will also be helped by the improved system for making offers to settle cases and attach ing stringent penalties to unreasonable responses to the offer. Again this is now open both to claimants and defence and the fact that solicitors have to keep both the other side and the judge informed of the costs means that weak cases are less likely to be continued because of the heavy financial penalty. Solicitors will need to prepare the groundwork for the claimant well. They must ensure that the advice they receive from experts is independent and accurate. On this basis they will need to advise clients accurately of the chances of winning their case and whether better remedy could be sought through mediation or the NHS complaints procedure.

The pre-action protocols are seen as having a wider role than simply preparing a case for litigation. Although they are not prescriptive about clinical governance, the protocols would suggest that prudent healthcare providers will have "effective co-ordinated, focused clinical risk management strategies and ......early identification and investigation of adverse outcomes". ${ }^{6}$ Although the protocols do not recommend changes to the codes of conduct of professionals in healthcare, Lord Woolf suggested that professional bodies should consider 
this. The need for clear documentation, regular audit, and clinical governance will provide an additional challenge to healthcare providers, who will have a responsibility to "put their house in order".

\section{ROLE OF THE PROCEDURAL JUDGE}

In order to speed up the conduct of medical negligence cases Lord Woolf said that judges would need training in medical issues and saw the development of a cohort of expert judges in this area. Such judges will be expected to "narrow and define issues as the case progresses, and will have extended powers to exclude evidence". ${ }^{1}$ In practice this now means that when parties do not cooperate judges can:

- Order the separate trial of an issue.

- Order that an expert is instructed jointly.

- Order a claimant or representative of the healthcare provider to appear before him/her.

- Order a case conference to define issues between parties in a multitrack case when the parties are unable to agree a timetable.

- Order parties at fault to pay the costs of wasted hearings.

The timetable for such activities can be very tight. Case conferences may be called with as little as three days notice and should happen shortly after the defence has been filed.

At the case conference the court may and will:

- Define the issues on which it requires evidence.

- Restrict the number of witnesses.

- Decide whether witnesses should be present for cross examination, in addition to their written statements.

- Identify any witness statement which will be disallowed because it has not been filed on time.

- Restrict the use of expert witnesses to what is reasonably required to resolve the issues.

Under the new rules it is the judge who will control the pace and content of the litigation process. As a result of these reforms the parties will be restricted in the manner of presentation of their cases. Some solicitors see that "if time limits are imposed without adequate regard to the commitment of the parties and their advisors .... It could provide a denial of justice altogether". ?

Some support for this view comes from the European Convention on Human Rights, ${ }^{8}$ which guarantees citizens the right to a fair trial:

"Article 6-right to a fair trial

1. In the determination of his civil rights and obligations or of any criminal charge against him, everyone is entitled to a fair and public hearing within a reasonable time by an independent and impartial tribunal established by law.

3b. to have adequate time and facilities for the preparation of his defence;

3d. to examine or have examined witnesses against him and to obtain the attendance and examination of witnesses on his behalf under the same conditions as witnesses against him;" (emphasis added).

These rights have now been embodied in the Human Rights Act 1998. Clearly any limitation in the right of the defence to call witnesses is likely to be interpreted as an infringement of article 6 (3d). However, in the judgment on Paul Leslie Daniels v Frederick Mark Walker (2000) Lord Woolf and Lord Latham expressed the view that judges should be "robust in resisting such arguments" and that counsel should act responsibly in their introduction to court. ${ }^{10}$

\section{ROLE OF EXPERT WITNESSES}

In medical negligence cases Woolf reluctantly accepted that both parties may need to instruct experts, but that meetings in private between such experts could help clarify areas of agreement and disagreement. He summarised this in his report by saying:

"In making my recommendations I intend to:

- Distinguish between the fact-finding and opinion-giving roles of experts;

- Increase the independence of experts and to reduce their partisan use by the parties;

- Encourage the use of experts to narrow rather than multiply the issues in dispute;

- Reduce the delay and expense resulting from the use of experts; and

- Ensure that the parties and the court reduce to a minimum the inconvenience caused to experts in the conduct of their professional life by having to give evidence". ${ }^{1}$

The basic premise underlying the reforms is that the role of the expert is to help the court and not to be partisan. As a result under the new Civil Practice Rules the court will not allow any questioning of an expert witness by another party, unless it is satisfied that there are reasonable grounds to suppose the expert's summary of his instructions is incomplete or inaccurate (part 35.10.4). Thus despite the openness advocated in the reforms it seems likely that instructions given to experts for fact finding or general advisory purposes will remain privileged. However, the fact that written questions can be put to the other side's expert witness and that answers can be treated as part of that expert's report does ameliorate to some extent the loss of ability to cross question that witness in court. This approach would suggest that "the bad old days of bald denials of negligence and evidence by ambush and stealth are over" ${ }^{11}$ However, Brahams is not entirely convinced and she feels there will continue to be informal telephone discussion of cases before instructions are issued and notes of such conversations will remain privileged.

The Code of Conduct for Experts produced under the guidance of Sir Louis Blom-Cooper has highlighted the dual status of the expert who will initially advise a litigating party, yet subsequently, as an expert witness, will produce a report for the court in which his or her overriding duty is to the court and not the client. ${ }^{12}$ This has particular consequences following David John Baron (Claimant) v Brian Lovell (Defendant) when it was confirmed that in certain circumstances a judge was entitled to direct at a pre-trial review that the medical evidence needed to determine issues relating to a claimant's personal injury action could be provided by the claimant's medical expert only (emphasis added).$^{13}$ In this situation the "right to a fair trial" embodied in the European Convention on Human Rights and so in the Human Rights Act may be under threat.

\section{ROLE OF THE NATIONAL HEALTH SERVICE} LITIGATION AUTHORITY

The role of the NHSLA in the process calls for some examination. The NHSLA was established to administer schemes in respect of the funding and handling of claims for clinical negligence against NHS bodies. ${ }^{14}$ In practical terms this has led to the development of an insurance scheme known as the Clinical Negligence Scheme for Trusts, which defines standards for clinical management and documentation. The purpose of these developments is to ensure that documentation and practice within individual trusts will fall within the standards anticipated by the new Civil Procedure Rules. In practice the NHSLA has become the clinical insurer for healthcare providers and as such it must give permission for any admissions of liability to be made. Failure to follow this process may prejudice their funding of negligence claims. An assessment of the case by the NHSLA can take up to four weeks and this time must be accommodated within the defendant's timetableadditional time is not given for this procedure and so the need 
to have swift responses from all involved in the case is paramount and trusts may be prepared to withdraw indemnity from employees who do not cooperate.

\section{ROLE OF MEDIATION}

The intention of the Civil Procedure Rules is to reduce the amount of litigation in the field of medical negligence. Indeed the aims of the pre-action protocols are:

- To maintain/restore the patient/healthcare provider relationship.

- To resolve as many disputes as possible without litigation.

Solicitors are required to make claimants "aware of the available options to pursue and resolve disputes and what each might involve" ${ }^{6}$ This includes the NHS Complaints Procedure and the Health Ombudsman, as well as mediation. However most interest has focused on mediation as this would allow disputing parties to fashion their own outcomes rather than have them imposed by a judge or arbitrator. A two year pilot scheme was launched in April 1995 which was designed to address many of the same concerns as Lord Woolf dealt with in his report..$^{15}$ Again its role was seen as narrowing the issues in dispute rather than fully resolving them. In all, 12 cases were mediated and in 11 a financial settlement was reached which ranged from $£ 5000$ to $£ 80000$. Other remedies that were granted to claimants included apologies and extensive explanations of medical decisions and the rationale for treatment decisions. This is particularly encouraging as doctors and other clinical staff have been traditionally reluctant to admit negligence or apologise to, or negotiate with, claimants for fear of damage to their professional reputations or career prospects. In the mediation pilots claimants were represented by a solicitor in 10 of the 12 cases, but the involvement of the responsible doctor depended upon his or her personality. Mediation seemed particularly valuable where there was considerable emotional overlay, the claimant had a long term relationship with the healthcare provider, and speedy resolution was possible. The pilot may be seen as a failure to some extent because of the low take-up. This was attributed to a lack of enthusiasm on the part of both claimants' solicitors, the NHS executive, and the NHSLA. ${ }^{16}$

\section{CONCLUSION}

To date there has been no exhaustive analysis of the impact of reforms on clinical negligence litigation. However, there have been two surveys of the impact of these reforms on other areas of litigation. In November 1999 Eversheds published the results of a survey of in-house counsel which reported that $76 \%$ of respondents had not detected any improvement in the litigation system and $70 \%$ had detected no improvement in the court process. ${ }^{17}$ Simanowitz has also expressed concerns about the failure of the new system to ensure that the patient attains an explanation, an apology, and/or reassurance about future standards, which are often said to be the main reasons for taking action. ${ }^{18}$ In addition a small claim is unlikely to be pursued because of the expense of hiring a lawyer and the general lack of interest of the Legal Aid Board in supporting cases in which the damages will be under $£ 5000$ or where the costs will be disproportionate to the damages.

It will be some time before the effect of the new civil procedure rules on clinical negligence litigation can be assessed. Whether they will lead to speedier and cheaper resolution of cases is as yet uncertain and their impact on the human rights of defendants may become the subject of litigation at the European Court of Human Rights. The impact on clinical practice and on the clinician accused of negligence is likely to be profound and he or she will be the subject of extensive media attention.

\section{REFERENCES}

1 Lord Woolf. Access to justice. London: Stationery Office Books and The Lord Chancellor's Department, July 1996

2 Vincent C, Young M, Phillips A. Why do people sue doctors? A study of patients and relatives taking legal action. Lancet 1994;343:1609-13.

3 Towse A, Danzon P. Medical negligence and the NHS: an economic analysis. Health Econ 1999:8:93-101.

4 The Ikarian reefer. 2 Lloyds Reports 1993 (68).

5 Leigh S. The new civil procedure rules. Clinical Disputes Forum Newsletter 1999;1:9-11

6 Civil Procedure Pre-Action Protocols. Clinical negligence protocol. The aims and objectives (http:www.open.gov.uk/lcd/civil/procrules_fin/ prot2-2htm).

7 Gardner C. Threats, problems and opportunities. The Expert 1999;4:10-12.

8 The European Convention on Human Rights. Strasbourg: Council of Europe, 1966.

9 Human Rights Act 1998

10 Paul Leslie Daniels v Frederick Mark Walker (2000). CA 3/5/2000. LTL 3/5/2000 Extempore (unreported elsewhere).

11 Brahams $\mathbf{D}$. The impact of the new civil practice rules on clinical negligence claims. Medico-Legal Journal 1999;67:7-8.

12 Jones B. Fair fees for the expert witness. The Personal and Medical Injuries Law Letter April 5-4, 2000.

13 David John Baron (Claimant) v Brian Lovell (Defendant) (1999). CA 2/7/99. LTL 27/7/99 Extempore: TLR 14/9/99.

14 Towns D. The National Health Service Litigation Authority framework document. Leeds: NHS Executive, 1996.

15 House of Commons Official Report. Hansard Vol $263 \mathrm{col} 918$ PQ4519/1994/95.

16 NHS Executive. Mediating medical negligence claims: an option for the future? (http://www.doh.gov.uk/mediation/executive_summary.htm). Leeds: NHS Executive, 2000

17 Eversheds. In-house survey (1999; quoted in http:// lawmoney.oyster.co.uk/publicnews/hotnews/news9711/ news $971125.1 \mathrm{html}$.

18 Simanowitz A. The interface between complaints and litigation. Clinical Disputes Forum Newsletter August 1999: 5. 